\title{
Commute distance and jobs-housing fit
}

\author{
Evelyn Blumenberg ${ }^{1} \cdot$ Fariba Siddiq $^{1}$ (D
}

Accepted: 13 January 2022 / Published online: 18 February 2022

(C) The Author(s) 2022

\begin{abstract}
Anecdotal evidence suggests that the affordable housing crisis is forcing households to seek lower cost housing in the outer reaches of major metropolitan areas, helping to explain recent increases in commute distance. To test this relationship, we use spatial regression to examine the relationship between the availability of affordable housing in close proximity to jobs (jobs-housing fit) and commute distance in the Los Angeles metropolitan area. The analysis draws on 2015 Longitudinal Employer-Household Dynamics (LEHD) OriginDestination Employment Statistics (LODES) by workplace supplemented with data from the 2013-2017 5-Year American Community Survey on affordable housing units. We find substantial variation in jobs-housing fit across Los Angeles neighborhoods. The imbalance is greatest in higher-income neighborhoods located along the coast and in Orange County, south of Los Angeles. Controlling for other determinants of commute distance, a higher ratio of jobs to affordable housing is associated with longer distance commutes. To address growing commute distances, policymakers must greatly expand and protect the supply of long-term rental housing particularly in job-rich neighborhoods.
\end{abstract}

Keywords Commuting $\cdot$ Low-wage workers · Affordable housing $\cdot$ Residential location

\section{Introduction}

Anecdotal evidence suggests that the growing affordable housing crisis in major metropolitan areas, such as Los Angeles, is forcing households to seek lower cost housing in the outer reaches of metropolitan areas, helping to explain the recent increase in commute distances (Dougherty and Burton 2017; Holder 2018; Lopez 2017; Sisson 2017; Tu 2015). Lopez (2017) writes, "Ungodly commutes, as we know, are not new to Southern California, which practically invented sprawl. People have long moved out of the city by choice, but with housing costs at historic highs, some now move by necessity." California is one of the few states where more than 10 percent of households make hour-long or even longer daily commutes (Schuetz 2019). Workers in California coastal communities-where

Fariba Siddiq

fsiddiq@ucla.edu

Evelyn Blumenberg

eblumenb@ucla.edu

1 Institute of Transportation Studies, UCLA Luskin School of Public Affairs, Los Angeles, USA 
housing prices are highest-spend 10 percent more time commuting than the national average (Taylor 2015).

With the growing suburbanization of both jobs and households, the number of jobs within close proximity of residents has declined in most metropolitan areas (Kneebone and Holmes 2016) and commute distance has grown (Crane 2007; McGuckin and Fucci 2018). In the Los Angeles metropolitan area, from 2000 to 2012 the number of jobs near the average resident decreased by 7.4 percent, with even higher increases in commute distance in high-poverty and majority-minority neighborhoods (Kneebone and Holmes 2016). At the same time, housing prices—both home and rental — have continued to climb, even in the midst of the COVID-19 pandemic (Joint Center for Housing Studies 2020a). High housing costs may limit the ability of lower-income households to act on their preferences for living in close proximity to their jobs (Levine 1998).

Despite suggestive evidence of the relationship between housing costs and commute distance, there are relatively few studies that document this association and its magnitude. This study aims to fill this gap in the literature by examining housing availability and commute distance of workers by wages in the Los Angeles metropolitan area (Los Angeles and Orange Counties), with a focus on the commute distance of and housing available for lower-wage workers. For this analysis, we draw on data from the 2015 Longitudinal Employer-Household Dynamics (LEHD) Origin-Destination Employment Statistics (LODES) supplemented with neighborhood-level data from the 2013-2017 5-year American Community Survey (ACS).

We find substantial variation in the jobs-housing fit, the availability of affordable housing in close proximity to low- and medium-wage jobs. The imbalance is greatest in higherincome neighborhoods located along the coast and in Orange County, the county just south of Los Angeles. Moreover, controlling for other determinants of commute distance, a higher ratio of jobs to affordable housing is associated with longer distance commutes. While the availability of housing in close proximity to jobs matters for higher-wage workers, the effect is significantly muted.

Longer distance commutes can be detrimental to families as well as to the environment - adversely affecting economic mobility, activity participation, health, and air quality. The results of this study underscore the importance of available and affordable housing in enabling workers to live close to their jobs, if they so choose. However, Southern California is facing an acute shortage of affordable housing. To address increasing commute distances, policymakers must greatly expand and protect the supply of long-term rental housing particularly in job-rich neighborhoods.

\section{Lower-wage workers and the commute}

Traditional explanations for commute distance rely on the monocentric city model and bidrent theory (Alonso 1964; Mills 1967; Muth 1969) which posit that wealthier households tend to live in the suburbs, distant from downtown and where land prices are relatively cheap allowing for the purchase of large homes on substantial lots. Conversely, low-income households concentrate in central cities when the income elasticity of demand for land is greater than the income elasticity of travel costs. The theory predicts that higher-wage workers will travel longer distances from the suburbs to jobs in and around central cities, while lower-wage workers will live in close proximity to job centers allowing for shorterdistance commutes. 
On average low-wage workers commute shorter distances than higher-wage workers (Antipova 2020; Blumenberg and King 2019; Horner and Schleith 2012; Plaut 2006; Schleith et al. 2016), potential evidence in support of this theory. However, the spatial structure of cities has changed over time with the decentralization of both households and employment (Frey 2018; Glaeser et al. 2001). Many cities have transformed from monocentric to polycentric. While some scholars have found polycentricity to be associated with shorter commutes (Gordon et al. 1986; Schleith et al. 2019; Sultana 2002; White 1990), others have found the opposite (Hamilton and Röell 1982; Schwanen et al. 2004). ${ }^{1}$

Although at a slower pace than among higher-income households, low-income households have suburbanized away from traditional central-city neighborhoods (Cooke and Denton 2015; Howell and Timberlake 2014; Kneebone and Garr 2010). As of 2019, more than half (52\%) of the metropolitan poor lived in the suburbs, up from 46 percent in 2000 (U.S. Census Bureau, Current Population Survey 2019). At the same time, most jobs can be found outside of downtown areas ( 8 out of 9 jobs) and outside of employment centers (6 out of 7 jobs) (Angel and Blei 2016). In Los Angeles, in 2010 almost 56 percent of jobs were located between 10 and 35 miles from downtown (Kneebone 2013).

These changes have had ambiguous effects on commute distance particularly among low-wage workers. The suburbanization of jobs and workers has contributed to the decline in the number of jobs within a typical commute distance, a change that has been most substantial for low-income and non-white workers (Antipova 2020; Kneebone and Holmes 2016). The spatial barrier between jobs and residents has received substantial scholarly attention. The topic dates back to Kain (1968) who, in what became known as the spatial mismatch hypothesis (SMH), argued that limitations on black residential choice combined with the steady dispersal of jobs from central cities resulted in joblessness, particularly among black men.

Subsequent studies show that lower-income households who do not own automobiles tend to live in dense, transit-rich neighborhoods where they can access jobs and other destinations within a reasonable travel time (Glaeser et al. 2008; Pathak et al. 2017; Shen 2001). Although job access in central cities remains higher than in the suburbs (Shen 2001), evidence suggests that the suburbanization of jobs is slowly eroding the central-city accessibility advantage (Hu 2015). The spatial gap between central-city residents and suburban employment may contribute to longer-distance commutes, if residents are unable to adjust their residential location (Martin 2001; Stoll 2005; Weber and Sultana 2008).

However, reverse commutes from central-city neighborhoods to suburban jobs are difficult and time consuming, potentially contributing to their relatively small share of all commute trips (10\%) (Davidson and Ryerson 2018). It is more likely that commute distances are growing in tandem with the increasing number of suburban poor who reside in neighborhoods with below-average numbers of jobs (Raphael and Stoll 2010) and have longer commutes than their urban counterparts (Allard and Paisner 2016; Blumenberg and King, 2019; Hu and Giuliano, 2011). Racial discrimination in both housing and employment contributes to these dynamics. For example, in their study of the spatial distribution of new jobs and residents in four metropolitan areas (Atlanta, Boston, Detroit, and Los Angeles), Stoll et al. (2000) show that residents of white suburban neighborhoods have far greater access to jobs compared to residents of black suburban neighborhoods. Moreover, research suggests that some suburban employers discriminate against black applicants, making it

\footnotetext{
1 Workers in Los Angeles have a shorter average commute distance and better jobs-housing balance than workers in other more sprawling metropolitan areas (Schleith et al. 2019).
} 
more likely that suburban black workers commute to central-city jobs than suburban white workers (Gottlieb and Lentnek 2001).

Finally, the lack of affordable housing may jeopardize the ability of low-wage workers to select into neighborhoods in close proximity to jobs. Numerous scholars have written about the relationship between commute distance and the jobs-housing balance-the location of employment relative to housing — asserting that more balanced cities and/or neighborhoods are linked to shorter commute distances (Cervero 1996; Peng 1997; Sultana 2002). A similar line of research centers on the relationship between the built environment (including jobs-housing balance) and "excess" commuting, defined as differences between the theoretical minimum and observed commuting distances (Hamilton 1982; Horner 2002).

In contrast, some scholars have argued that efforts to increase jobs-housing balance would have limited effects on travel, since factors other than proximity to employment (e.g. larger houses and lot sizes, improved neighborhood amenities) play a larger role in residential location choice (Giuliano 1991). Moreover, low-wage workers typically have less employment stability and, therefore, higher rates of job turnover than higher-wage workers (Lane 2000). Consequently, they are less likely than more stable workers to select neighborhoods based on the location of their current jobs and, all else equal, more likely to live farther from work (Crane 1996).

The primary benefit of jobs-housing balance may lie less in reducing overall vehicle miles of travel and much more in increasing the range of locational choices available, particularly for households with limited resources (Levine 1998). In some metropolitan areas, the lack of affordable housing may pose a significant barrier to locational choices. As we note above, housing prices—both home and rental—continue to climb (Joint Center for Housing Studies 2020a), contributing to affordable housing crises in large coastal cities (Murray and Schuetz 2018). For example, data from the 2017 5-year American Community Survey show that 56 percent of renters in the Los Angeles metropolitan area were cost burdened, spending more than 30 percent of their incomes on rent, a percentage higher than all but two of the 100 largest metropolitan areas in the country (Miami-Fort Lauderdale, FL and Riverside-San Bernardino, CA) (Joint Center for Housing Studies 2020b). In high-cost regions, the availability of affordable units relative to the location of low-wage jobs varies significantly across jurisdictions and neighborhoods within them (Benner and Karner 2016; Zonta 2020), potentially making it difficult or, in some cases, impossible for low-income households to select into neighborhoods located close to their jobs should they so choose.

\section{Methodology}

In this analysis, therefore, we examine the relationship between the availability of affordable housing and commute distance by workplace location. We hypothesize that the availability of affordable housing - among other characteristics-is associated with shorter commute distances, particularly for low-wage workers. We test this relationship using data for the Los Angeles Metropolitan Statistical Area (MSA) which includes both Los Angeles and Orange counties.

The analysis relies on data from the 2015 Longitudinal Employer-Household Dynamics (LEHD) Origin-Destination Employment Statistics (LODES), state administrative data assembled by the Center for Economic Studies at the U.S. Census Bureau (U.S. Census Bureau 2015). The LODES data provide information on the location of workers, the 
location of jobs, and the location of workers relative to their jobs. Research shows that characteristics of workplace location are more strongly associated with commute behavior than characteristics of residential location (Chacon-Hurtado et al. 2019; Hu and Schneider 2017).

The LODES data report the workplace and residence locations at the census block level. The commute distance calculations are based on network distance, since variation in topography (e.g., mountains, bodies of water) and, consequently, the road network influence route choice. We identified the shortest road network path as of 2018 using the Open Source Routing Machine (OSRM), an open-source router, and the latitude and longitude coordinates for each block origin and destination pair.

We supplement these data with housing data from the 2013-2017 5-year American Community Survey. While these data are available at the block group level, we use the census tract-level data so as to minimize margins of error and, therefore, aggregated the commute distance data to this geography. The LODES data report jobs in three wage categories allowing us to calculate the network commute distance separately for lower-wage workers (with earnings $\$ 1,250$ or less), medium-wage workers (with earnings $\$ 1,251 /$ month to $\$ 3,333 /$ month), and higher-wage workers (with earnings more than $\$ 3,333 /$ month).

We then model median commute distance by workplace census tract and by wage group as a function of three types of characteristics-location, employment, and housing. ${ }^{2}$ The models take the following basic form:

$$
\text { Commute distance to workplace census tract }=f(L, E, H)
$$

where $L$ denotes a vector of locational characteristics (distance from downtown, location in an employment center, location in an urban neighborhood, location within half mile of a rail station, distance to downtown*tract's location in a job cluster), $E$ denotes a vector of employment characteristics (the number of low- and medium-wage jobs relative to high-wage jobs, job competition denoted by the ratio of jobs and employed residents in the tract), and $H$ denotes a vector of housing characteristics (median home value, vacancy rate, jobs-housing fit, and jobs-housing ratio).

To identify whether census tracts are located in an employment cluster/center, we follow the method used by Giuliano and Small (1991) and Giuliano et al. (2007). A tract is located in an employment cluster/center if it is (a) in a set of contiguous tracts (b) with a minimum 10 employees per acre and (c) together the tracts have a minimum total employment of 10,000. Commute distance into major job centers tends to be longer than commute distance into secondary job centers (Cervero and Wu 1998; Giuliano 1991). We test this by including an interaction term that relates distance to downtown and the tract's location in a job cluster.

We identify urban and suburban tracts using the seven neighborhood types developed by Voulgaris et al. (2017). Urban neighborhoods are those that fall into three categories: old urban, mixed use, and urban residential. High activity densities in these neighborhoods are associated with less personal miles of travel and greater use of public transit. Suburban neighborhoods are those that are established suburban, patchwork, and new development.

Station locations from the Los Angeles County Metropolitan Transportation Authority (Metro) allow us to identify tracts located a half mile from a rail station. Rail-adjacent

\footnotetext{
${ }^{2}$ Seven out of 2,929 census tracts $(0.24 \%$ of the census tracts) in the Los Angeles MSA did not have any employment reported in the LODES dataset and were excluded from this analysis.
} 
neighborhoods are varied in location and with respect to their mix of housing and jobs. For example, in their study of fixed-route transit station areas in 39 U.S. regions, Renne et al. (2016) find that 57 percent of the station areas in Los Angeles are low-density, less walkable neighborhoods. Therefore, the relationship between rail adjacency and commute distance is difficult to predict.

Historically, exclusionary land use regulations - minimum lot size requirements, single family zoning, minimum square footage requirements, and costly building codes-have been used to limit the availability of affordable housing, and have contributed to the segregation of households by income, race, and other life circumstances (Whittemore 2020). Studies show that housing costs and availability are associated with commute distance, influencing the types of workers that can select into neighborhoods in close proximity to their jobs (Cervero and Wu 1998). To test this association, our models include median home value and housing vacancy rates (the percent of vacant housing units).

In this analysis, we focus on the relationship between commute distance and jobs-housing fit, a measure of the adequacy of housing units of different prices matched to the wage characteristics of local workers. We examine commute distance among workers in the three wage groups available in the dataset: low $(<\$ 1,250 /$ month), middle $(\$ 1,251-\$ 3,333 /$ month $)$ and high ( $>\$ 3,333 /$ month). ${ }^{3}$ We also test the influence of jobs-housing fit relative to a general jobs-housing ratio measure (the number of all jobs relative to housing units).

To calculate jobs-housing fit, we follow the method used by Benner and Karner (2016). In addition to their low-wage jobs-housing fit metric, we also calculate a medium-wage jobshousing fit measure to test whether housing affordability is associated with commute distance among workers in other wage categories. Recent data suggest that rising rents increasingly burden even middle-income households (Joint Center for Housing Studies 2020b).

For each of the metrics, we use a linear distance decay function to weight jobs and affordable rentals in each census tract:

Low-wage jobs-housing fit for census tract ${ }_{i}=\frac{\sum_{j} \text { Low-wage jobs }_{j}+\sum_{k} \text { Low-wage jobs }_{k}(-0.4 \mathrm{~d}+1.2)}{\sum_{j} \text { Affordable rentals }_{j}+\sum_{k} \text { Affordable }_{\text {Rentals }}(-0.4 \mathrm{~d}+1.2)}$

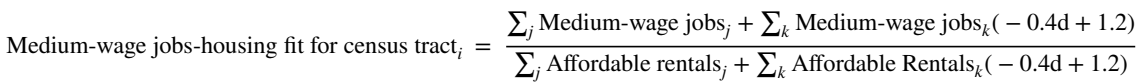

where $j$ indicates the block groups with centroids within 0.5 miles of the population weighted centroid of census tract $i$. $k$ indicates the block groups with centroids between 0.5 and 3.0 miles of the population weighted centroid of census tract $i$, and $d$ is the straight line distance between population-weighted centroids of census tract $i$ and block-group $k^{4}$

\footnotetext{
3 Microdata from the 2015-2019 5-Year American Community Survey show that among employed workers 16 years and older, 24 percent have wages below $\$ 1,250,30$ percent have wages between $\$ 1,250$ and $\$ 3,333$, and 46 percent of wages greater than $\$ 3,333$ (Ruggles et al. 2021).

4 There is no standard definition of the geographic area suitable for measuring jobs-housing balance. At some spatial scale all housing and workers are in perfect balance. Benner and Karner (2016) use the 0.5 and 3-mile buffers based on walking and biking as the primary means of travel to work, drawing from both national and California data to support the buffers. Few workers in the Los Angeles MSA bike or walk to work (3.3\%) (Ruggles et al. 2021); however, the ability to walk or bike to work can serve as one measure of a local jobs-housing shed. Studies also show that statistical models based on an impedance factor are not particularly sensitive to the specific value (Blumenberg and Ong 1998; Bunel and Tovar 2014).
} 
Benner and Karner (2016) used household incomes of \$30,000 a year (two times the $\$ 1,250 /$ month threshold of the low-wage job category) as the low-income threshold and $\$ 750 /$ month $(30 \% \times \$ 30,000 / 12)$ as the rent threshold for affordable rentals for low-income households. To enable comparisons of our findings across metropolitan areas, we use the same threshold for affordable rentals in Eq. (2) as do Benner and Karner (2016). Data on the household incomes of workers by census tract are not available. However, as a robustness check, we used data from the 2013-2017 American Community Survey Public Use Microdata Sample to calculate the median household income of renters in the Los Angeles metropolitan area with earnings less than $\$ 15,000(\$ 1,250 * 12)$; their median household incomes were $\$ 35,746$ (Ruggles et al. 2021).

We set the medium-income threshold at $\$ 79,992$ a year of household income (two times the $\$ 3,333 /$ month threshold of the medium-wage job category) and the rent threshold for affordable rental for medium-income households at $\$ 1,999.8 /$ month $(30 \% \times \$ 79,992 / 12)$. Rental units with rent less than $\$ 1,999.8 /$ month and units with no cash rent are considered affordable rentals in Eq. (3). The measure is cumulative and includes units that are affordable to both middle- and low-income households. Since the 2007-09 financial crisis, renting has become increasingly common among middle-income households (United States Government Accountability Office 2020), who in tight housing markets can compete with low-income households for available units (Somerville and Mayer 2003).

As we note above, we also calculate jobs-housing ratio considering all jobs and housing units for each census tract. We apply the linear distance-decay function as follows.

$$
\text { Jobs-housing ratio for census tract }{ }_{i}=\frac{\sum_{j} \text { All jobs }_{j}+\sum_{k} \text { All jobs }_{k}(-0.4 \mathrm{~d}+1.2)}{\sum_{j} \text { All housing units }_{j}+\sum_{k} \text { All housing units }_{k}(-0.4 \mathrm{~d}+1.2)}
$$

where $j$ indicates the block groups that have centroids within 0.5 miles of the population weighted centroid of census tract $i$, $k$ indicates the block groups that have centroids between 0.5 and 3.0 miles of the population weighted centroid of census tract $i$, and $d$ is the straight line distance between population-weighted centroids of census tract $i$ and block-group $k$.

Figure 1 shows the mean of the median commute distances across census tracts and by worker wages. As other studies find, the data reveal a positive relationship between wages and commute distance. Low-wage workers commute just under 11 miles while higherwage workers commute more than 14 miles, 32 percent longer. Table 1 includes descriptive statistics for the dependent and independent variables in the regression models. Four of the variables-median commute distance, median home value, vacancy rate, and distance to city hall-are positively skewed and, therefore, required logarithmic transformations to approximate a normal distribution.

We construct three models with the following dependent variables: (1) commute distance of lower-wage workers, (2) commute distance of medium-wage workers, and (3) commute distance of higher-wage workers. We first estimate ordinary least square (OLS) regressions. For all of the models, the Moran's I test for regression residuals suggests the presence of spatial autocorrelation and the use of spatial regression to address the issue of spatial autocorrelation.

Spatial autocorrelation can result from (1) the correlation of error terms across the spatial entities because of omitted explanatory variables, or from (2) the dependence between the dependent variable of adjacent spatial entities. The first issue can be addressed using a 


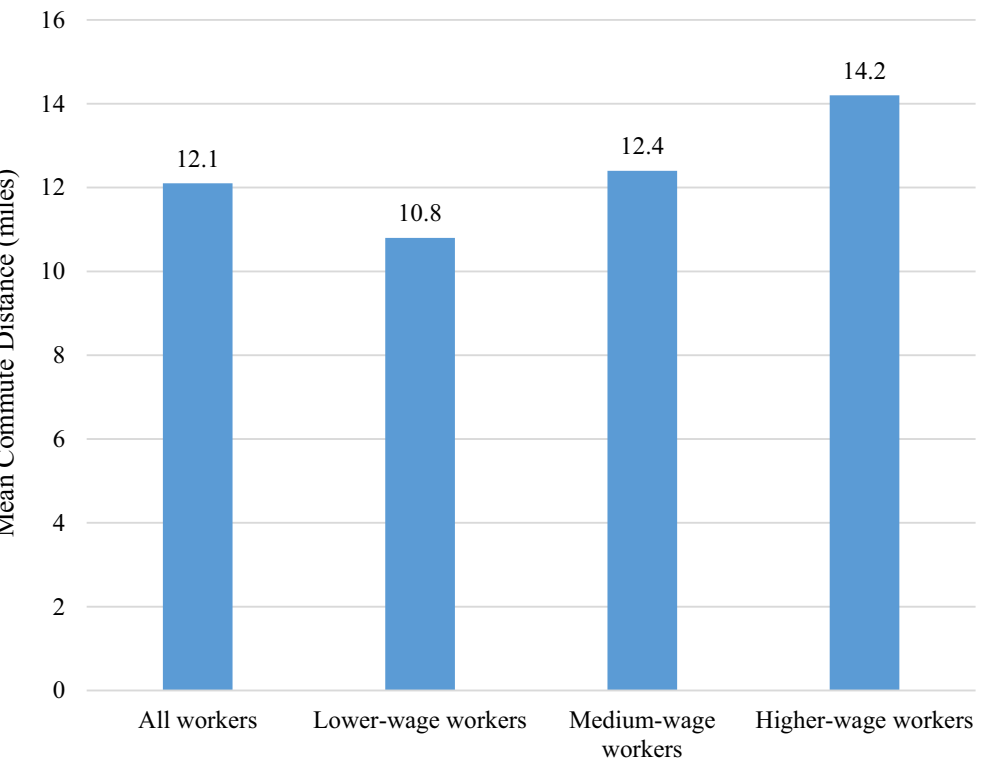

Fig. 1 Mean Median Commute Distance by Worker Wage Group

spatial error model and the second can be addressed by using a spatial lag model (Golgher and Voss 2016). To determine the appropriate model form, we use the Lagrange multiplier (LM) diagnostics. The statistics and significance of the robust and non-robust forms of the LM indicate that the spatial lag model was the appropriate choice.

Determining the spatial relationship among census tracts requires specification of a spatial weight matrix (Anselin 2002). We examined regression estimates based on the first-order rook contiguity, first-order queen contiguity, and distance-based spatial weights using a 3-mile distance threshold. The spatial weight matrix based on firstorder queen contiguity provided the best fit. The criteria of first-order queen contiguity of shared common edge or common vertex are also reasonable definitions for assigning spatial entities as neighbors (Kawabata and Shen 2007).

The spatial lag model for all of our three models takes the following basic form:

$$
y=\rho W_{y}+X \beta+\varepsilon
$$

where, $W$ is a $n \times n$ spatial weights matrix, $W_{y}$ is the spatially lagged dependent variable, $\rho$ is the spatial autoregressive parameter, $X$ is an $n \times k$ matrix of observations of the independent variables, $\beta$ is a $k \times 1$ vector of regression coefficients, and $\varepsilon$ is a $n \times 1$ vector of error terms. 


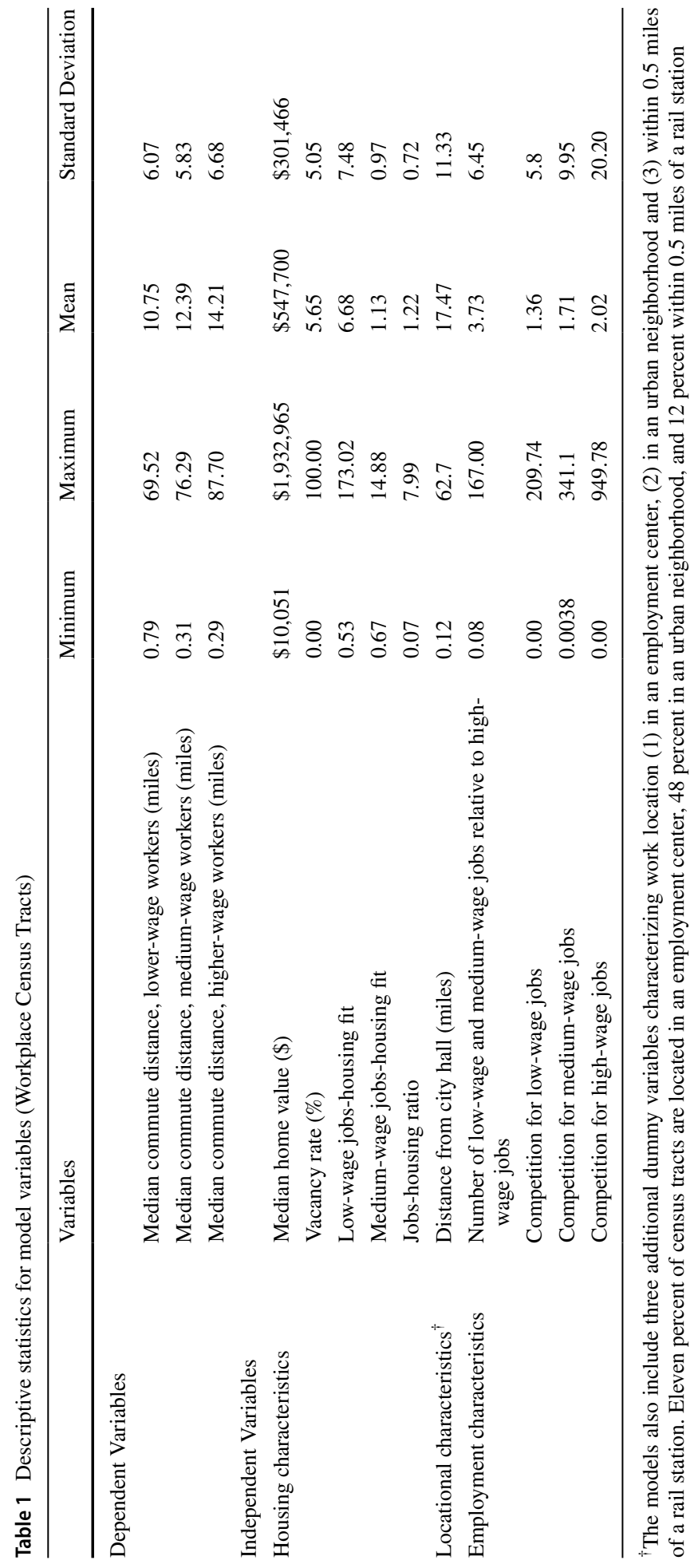




\section{Data limitations}

There are a few limitations to the LODES data. ${ }^{5}$ First, employees who have more than one job are included in the dataset multiple times, potentially influencing the jobs-housing metrics (Horner and Schleith 2012). Further, multiple job holders likely have household incomes that are greater than the data would suggest and, if they do, would be able to afford higher-priced housing. National data suggest that the percentage of multiple job holders has increased since the Great Recession but remains relatively small, approximately 7.5 percent of all workers (Bailey and Spletzer 2021).

Second, as we describe above, the data are drawn from administrative records from the unemployment insurance (UI) program which poses two issues. While the data coverage is substantial—far more extensive than similar data from the Census Transportation Planning Products drawn from the Census and the American Community Survey-some employers are exempt from UI participation (State of California. Employment Development Department nd) and others operate in the informal sector specifically to avoid paying taxes such as UI (Nightingale and Wandner 2011). Moreover, and important for this analysis, while employers are required to report job locations, in some cases the location may not be the site at which employees work but rather the administrative headquarters of the firm. To minimize this issue, employers with multiple sites are required to submit a Multiple Worksite Report. The non-compliance rate among multi-unit employers is less than six percent (Graham et al. 2014).

Finally, the data do not indicate whether and how often workers physically travel to their places of employment, a topic of great interest during the COVID-19 pandemic. Analysis of data from the 2013-2017 American Community Survey shows that just over five percent of all workers in the Los Angeles MSA work from home. This percentage has increased over time and likely will increase further in the aftermath of the pandemic, particularly among high-skilled workers who are able to telecommute (Dey et al. 2020), potentially weakening the relevance of these data for transportation purposes.

\section{Jobs-housing fit}

Figure 2 shows the percentage of workers by wage group and the presence of cost-appropriate housing. Only four percent of lower-wage workers work in neighborhoods where the number of affordable rentals exceeds the number of low-wage jobs. In comparison, 58 percent of medium wage workers and 77 percent of higher-wage workers work in neighborhoods where cost-appropriate housing exceeds the total number of jobs.

The spatial distribution of housing relative to workers varies across neighborhoods and by worker wage. Figure $3 \mathrm{a}-\mathrm{c}$ include maps of our three jobs-housing fit measures by quintile. Areas in blue have more housing relative to jobs and areas in red have more jobs relative to affordable housing. For lower-wage workers, as we might expect, the supply of affordable units relative to low-wage jobs tends to cluster in the central part of the metropolitan area in close proximity to downtown Los Angeles and in the north-south corridor between downtown Los Angeles and the City of Long Beach, including the large port

\footnotetext{
${ }^{5}$ For a detailed discussion of the differences between the LODES data and data from American Community Survey commuting products, see Graham et al. (2014).
} 


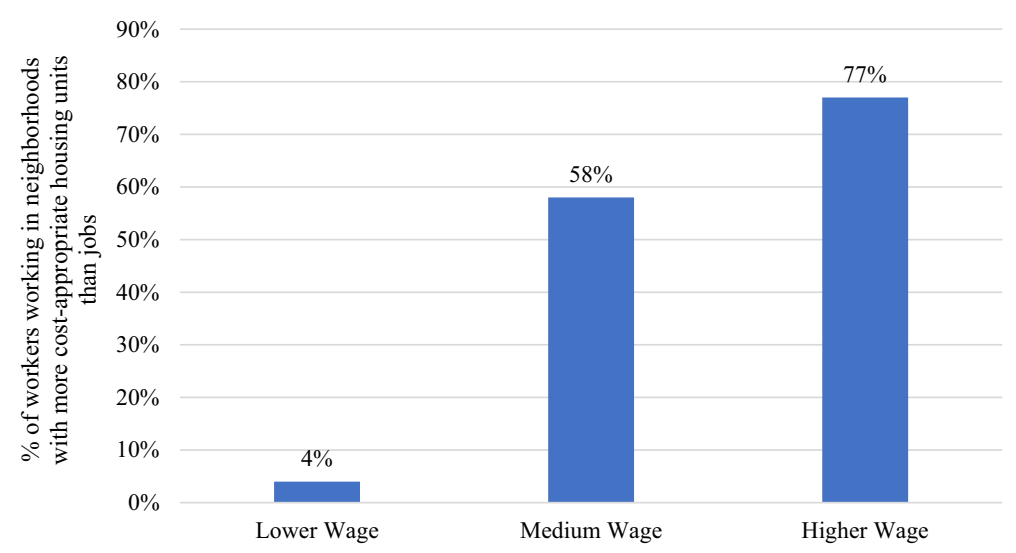

Fig. 2 Percentage of Workers Working in Neighborhoods in which Cost-Appropriate Housing Units Exceed the Number of Workers

complex to the south. There is also a concentration of affordable rentals relative to lowwage jobs in Lancaster and Palmdale, suburban cities located 70 miles north of downtown Los Angeles. Neighborhoods along the coast and toward the south in Orange County, more affluent parts of the region, tend to have less affordable housing relative to jobs.

In addition to these areas, Fig. $3 \mathrm{~b}$ shows that medium-wage workers can more easily locate housing in neighborhoods in the San Fernando Valley (immediately north of the LA basin) and near Anaheim in Orange County. Finally, Fig. 3c depicts the relationship between all housing and all jobs. Although the pattern is less obvious than in the previous two maps, a comparison across all three maps shows that for higher-wage workers there are additional neighborhoods with a surplus of housing relative to jobs. Of course, some neighborhoods - regardless of worker wages-have fewer housing units than jobs. These trends are a product of historical zoning regulations aimed at separating conflicting land use and neighborhood anti-development efforts often motivated by preservation and environmental interests (Fischel 2004; Glaeser 2017).

\section{Affordable housing and commute distance}

Table 2 presents the results of the OLS and spatial lag models. The Akaike information criteria (AIC) for the spatial lag models for all wage categories are lower than the AIC values for the corresponding OLS models. This suggests that the spatial lag models have better model fits than the OLS models. The magnitudes of effects of the independent variables on commute patterns in all the models are smaller for the spatial lag model than the OLS model. The R-squared values of the OLS models suggest that the variables explain the commute distance of lower-wage and medium-wage workers better than that of higherwage workers, likely because higher-income households have the means to act on a more diverse set of preferences (e.g., living by the beach, working from home, etc.). 
Fig. 3 Jobs-Housing Fit, Los Angeles-Orange Metropolitan Area (Quintiles) (a) Low-Wage Jobs-Housing Fit (b) MediumWage Jobs-Housing Fit (c) JobsHousing Ratio (a)

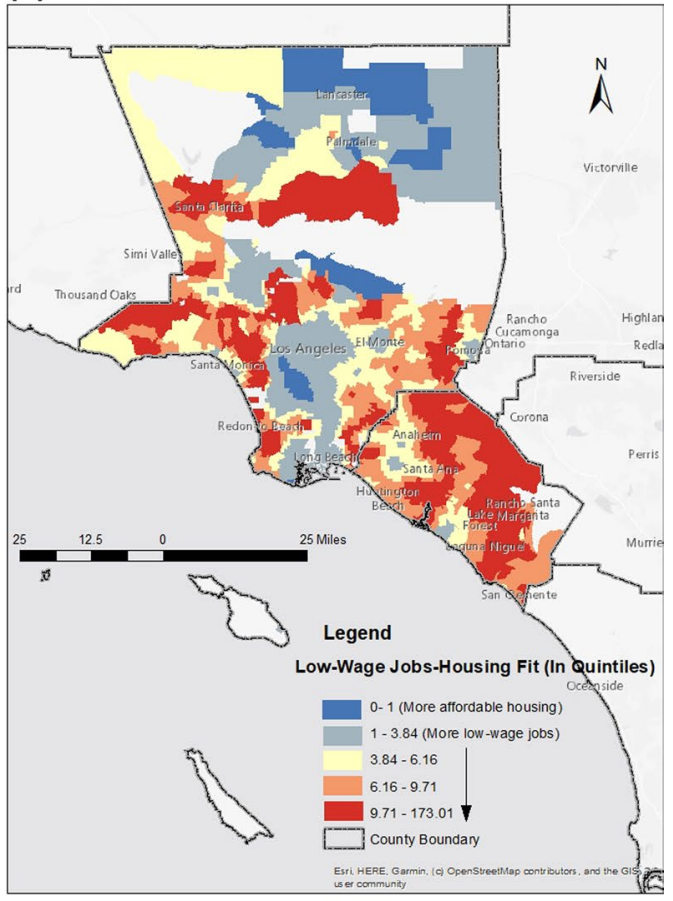

(b)

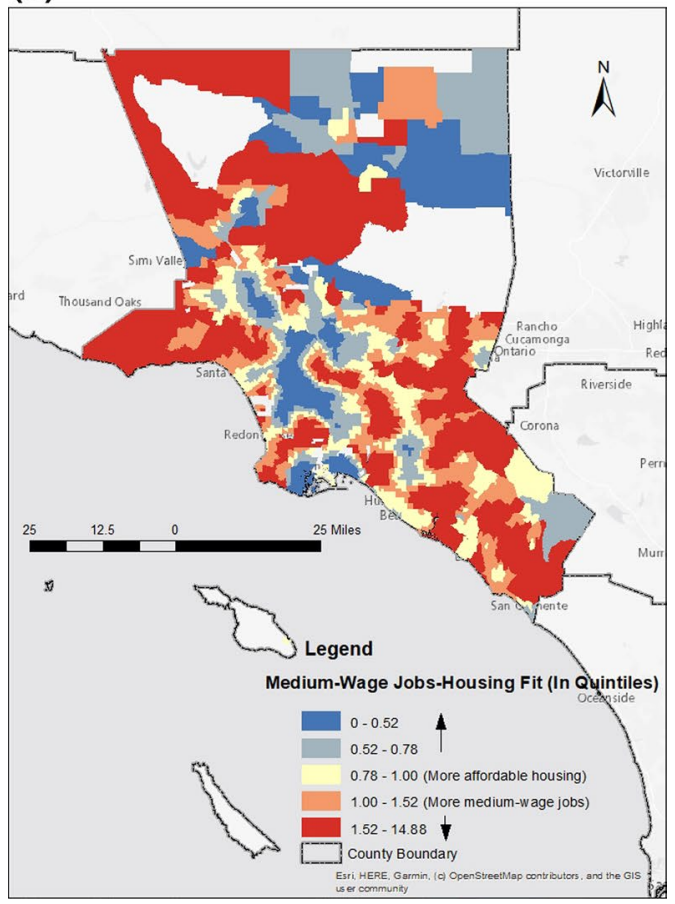


Fig. 3 (continued)

(c)

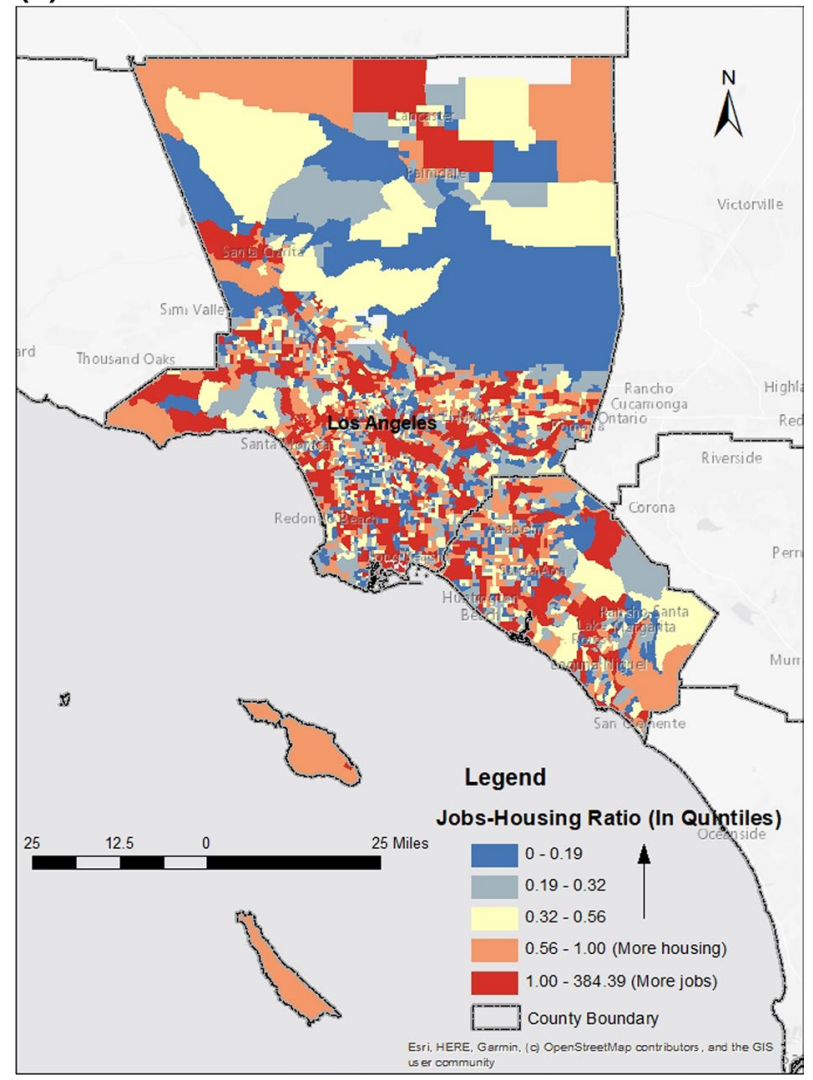

In general, the control variables perform as we predicted. All else equal, workers who worked in census tracts that are in an employment center had longer commutes, a finding consistent with earlier research (Giuliano and Small 1991). Distance to downtown is positively associated with commute distance; however, the interaction term between distance to downtown and employment center is negative. In other words, longer commutes to jobs located in downtown are partially offset in job centers located in other parts of the region.

Controlling for other variables, the association between the urban neighborhood dummy variable and commute distance is negative. As we might expect, workers who worked in urban census tracts had shorter commutes than workers in other locations. Urban neighborhoods are denser and have more diverse land use than their suburban counterparts and, therefore, jobs and residences are more likely to be located in close proximity (Cheshire et al. 2018; Schleith et al. 2016).

Commute distance was longer for workers in jobs located within half mile of a rail station, although this variable is not significant in the medium and higher-wage worker models. Rail transit may improve regional connectivity and, therefore, contribute to the growing separation of jobs and housing (Gao et al. 2019). With respect to lower-wage workers, gentrification around rail station areas may limit their ability to remain or to move into these neighborhoods, although the evidence of this behavior is mixed and may vary across station areas (Baker and Lee 2019; Boarnet et al. 2018; Dominie 2012; Kahn 2007). 


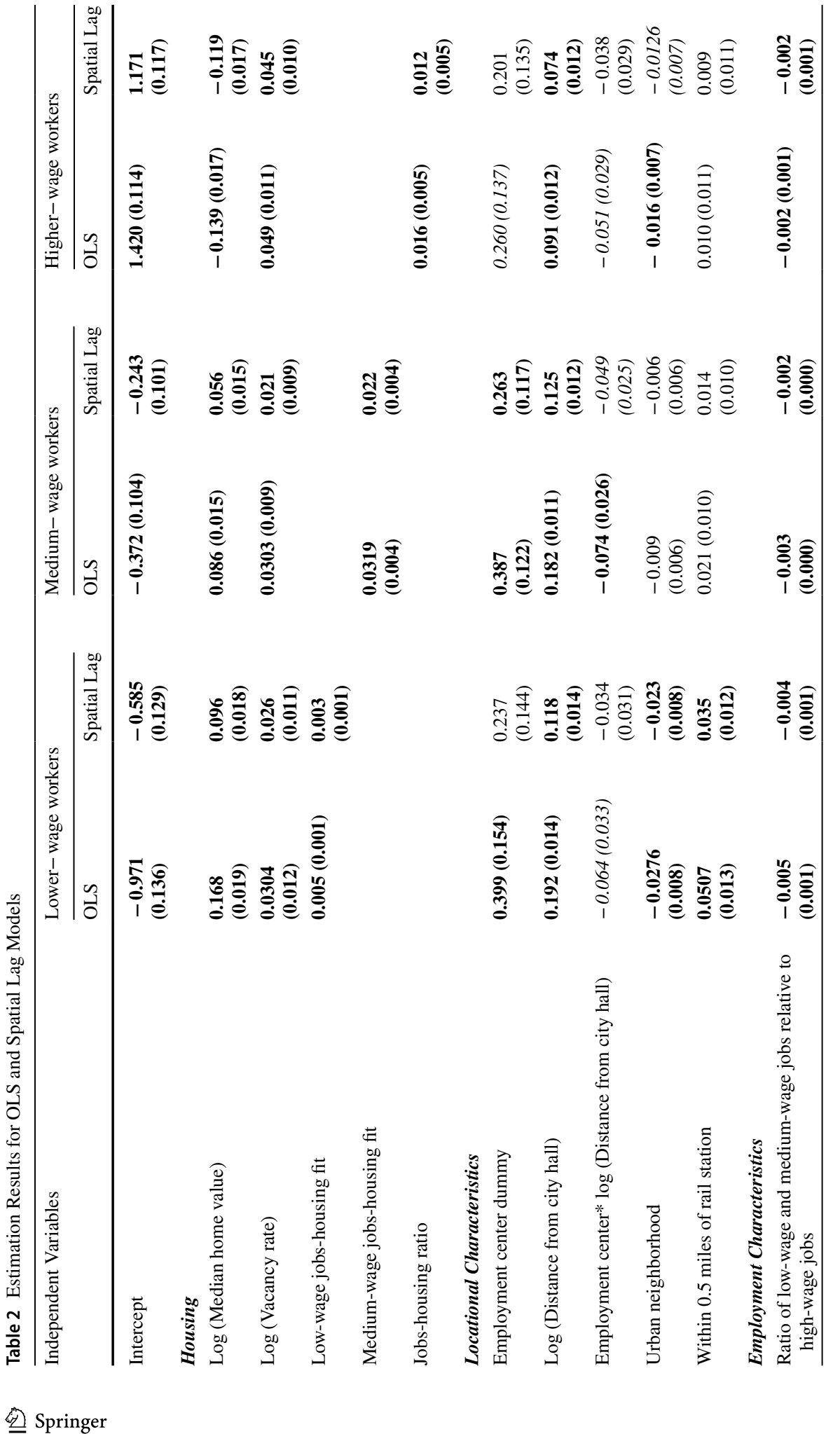




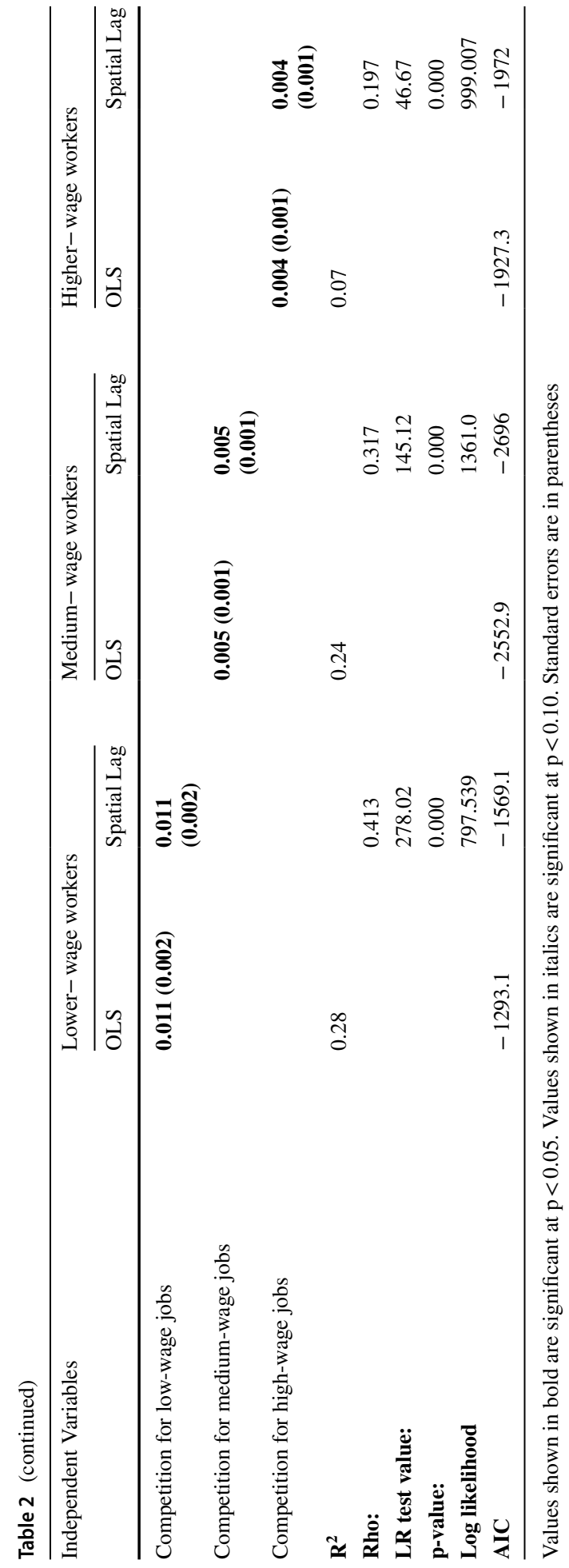




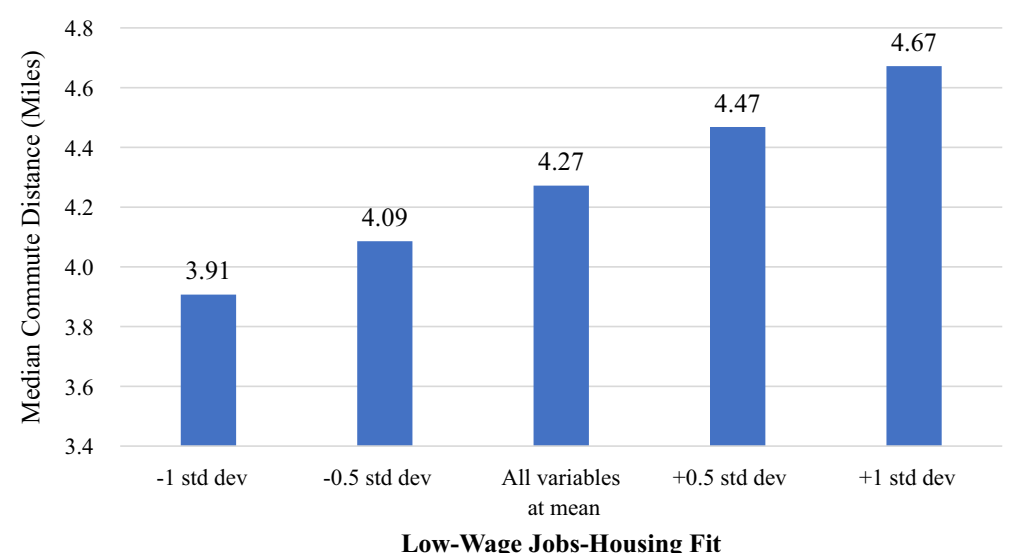

Fig. 4 Commute Distance of Lower-Wage Workers Relative to Change in Low-Wage Jobs-Housing Fit Metric

The association between commute distance and competition for wage-appropriate jobs is positive indicating that census tracts with more jobs relative to employed residents likely attract workers from more distant neighborhoods. On average, an increase in the proportion of low- and medium-wage jobs compared to high-wage jobs in a tract was associated with shorter commutes. Since lower-income workers commute shorter distances than higherincome workers (Blumenberg and King 2019), workers in census tracts with higher numbers of low-wage jobs tend to have shorter average commute distances. The effect of this variable also suggests a role for skills match in residential location choice.

All of the housing variables are statistically significant in the models for all three wage categories. The distance traveled by lower- and medium-wage workers to workplace locations is positively associated with the median home value at the workplace census tract. The lack of reasonably priced housing options near employment locations likely forces lower- and medium-wage workers to live far from job locations and, consequently, leads to longer commutes. For higher-wage workers, however, commute distance is inversely related with median home value. Higher-wage workers are less likely to face cost barriers in the housing market. Commute distance and vacancy rates are positively related for all wage categories. Restrictive land use regulations limit the supply of affordable housing (Cervero 1989) and, at the same time, are associated with higher vacancy rates and longer distance commutes (Cheshire et al. 2018).

We are particularly interested in the match between the housing affordability and jobs by wage group. The jobs-housing fit metric for lower- and medium-wage workers is positively associated with commute distance. In addition, the availability of all jobs relative to all housing is positive and statistically significant in the higher-wage workers model. However, compared to the jobs-housing fit variables in the previous two models, the availability of all jobs relative to all housing contributes far less to explaining commute distance relative to the other variables in the model. ${ }^{6}$ Figure 4 shows the effect of a one standard deviation change in the jobs-housing fit metric below and above the mean on the commute

\footnotetext{
${ }^{6}$ This finding is drawn from the standardized coefficients of the OLS models (Table 1 in the appendix).
} 
distance of lower-wage workers, holding all other variables at the mean. ${ }^{7}$ A large shift in the jobs-housing fit metric results in 19.4 percent change in the commute distance of lowerwage workers.

Finally, we tested the relationship between commute distance for lower- and mediumwage workers and the jobs-housing ratio (without accounting for fit). The findings from these models are in Table 2 in the Appendix. The jobs-housing variable is statistically significant in both models; however, the models with jobs-housing fit yield higher R-squared values, underscoring the importance of the match between workers by wage and the local availability of affordable housing.

\section{Conclusion}

Many workers with longer distance commutes are compensated for their travel with higher wages, lower-cost housing, or other neighborhood amenities (e.g. better schools, more open space, etc.). However, the models presented here suggest that holding other workplace characteristics constant, the character and affordability of housing may not adequately meet worker demand-particularly demand from lower- and medium-wage workers. Neighborhoods with more affordable housing relative to jobs are associated with shorter commutes, suggesting that the availability of affordable housing allows, at least some households, to self-select into neighborhoods in close proximity to their jobs.

Additional data and research are needed to further substantiate and build on these findings. A principal weakness with the LODES data is the wage categories. The three categories are defined nationally and, therefore, may not adequately capture three distinct segments of the labor market in some, particularly high-cost, metropolitan areas. The Census Bureau also does not adjust the wage categories for inflation, limiting the ability of researchers to track changes over time in the commute distance of workers by wages. Finally, the origin-destination data include only limited information on worker characteristics (age group, wage category, and major employment sector) further narrowing the usefulness of the data. These limitations combined with those discussed previously suggest needed improvements in the organization and availability of these data. They also underscore the importance of supplementing research based on aggregate data with studies that draw from other data sources. The gold standard for this line of research would be longitudinal microdata that follow workers and their residential and employment choices over time.

The findings from this study, however, suggest that the lack of affordable housing contributes to longer-distance commutes, potentially with adverse consequences particularly for lower-wage workers. Evidence shows that lower-skilled workers benefit from living in high-employment-growth areas, suggesting that longer-commutes may negatively affect their economic mobility (Acolin and Wachter 2017). Workplaces located further from home may make it difficult for parents to juggle household and work responsibilities (Hanson 2010), potentially resulting in higher rates of job turnover. Longer distance commutes can burden households by taking up hours of the day that could be devoted to other productive uses such as additional paid work or spending

\footnotetext{
7 The dummy variables for location in an employment center, an urban neighborhood, and within 0.5 miles of rail station are held at one for the estimation of the effect of jobs-housing fit on commute distance in Fig. 4.
} 
time with family and friends (Morris et al. 2020). Finally, long distance commutes, particularly those in automobiles, can have negative health impacts such as death and injury from crashes and cardio-respiratory illnesses caused by air pollution (Douglas et al. 2011).

The findings from this study underscore the importance of policy efforts to protect and expand the supply of long-term rental housing particularly in job-rich neighborhoods located in large and expensive coastal cities. How best to do this is currently the subject of substantial debate (Manville et al. 2020; Rodríguez-Pose and Storper 2020) and beyond the scope of this study. However, broad strategies include the creation and preservation of dedicated affordable housing units, zoning changes that allow for additional housing development, the relaxation of housing standards to facilitate higher-density development, increased government housing subsidies, and tenant protections.

\section{Appendix 1}

See Tables 3 and 4

Table 3 Standardized Coefficients for OLS Models

\begin{tabular}{lccc}
\hline & $\begin{array}{l}\text { Lower-wage } \\
\text { workers }\end{array}$ & $\begin{array}{l}\text { Medium- } \\
\text { wage } \\
\text { workers }\end{array}$ & $\begin{array}{l}\text { Higher-wage work- } \\
\text { ers }\end{array}$ \\
\hline (Intercept) & 0.000 & 0.000 & 0.000 \\
Log (Median home value) & 0.158 & 0.105 & -0.167 \\
Log (Vacancy rate) & 0.044 & 0.057 & 0.090 \\
Low-wage jobs-housing fit & 0.170 & & \\
Medium-wage jobs-housing fit & & 0.171 & 0.066 \\
Jobs-housing ratio & & & 0.463 \\
Employment center dummy & 0.553 & 0.697 & 0.173 \\
Log (Distance from city hall) & 0.284 & -0.621 & -0.425 \\
Employment center* Log (Distance from city hall) & -0.415 & -0.025 & -0.047 \\
Urban neighborhood & -0.062 & 0.040 & 0.018 \\
Within 0.5 miles of rail station & 0.073 & -0.098 & -0.061 \\
Ratio of low-wage and medium-wage jobs relative & -0.137 & & \\
$\quad$ to high-wage jobs & & & 0.082 \\
Competition for low-wage jobs & 0.119 & & \\
Competition for medium-wage jobs & & & \\
Competition for high-wage jobs & & & \\
\hline
\end{tabular}


Table 4 Estimation results for OLS models for Lower-Wage and Medium-Wage Workers' Commute Distance with Jobs-Housing Ratio as the Variable of Interest

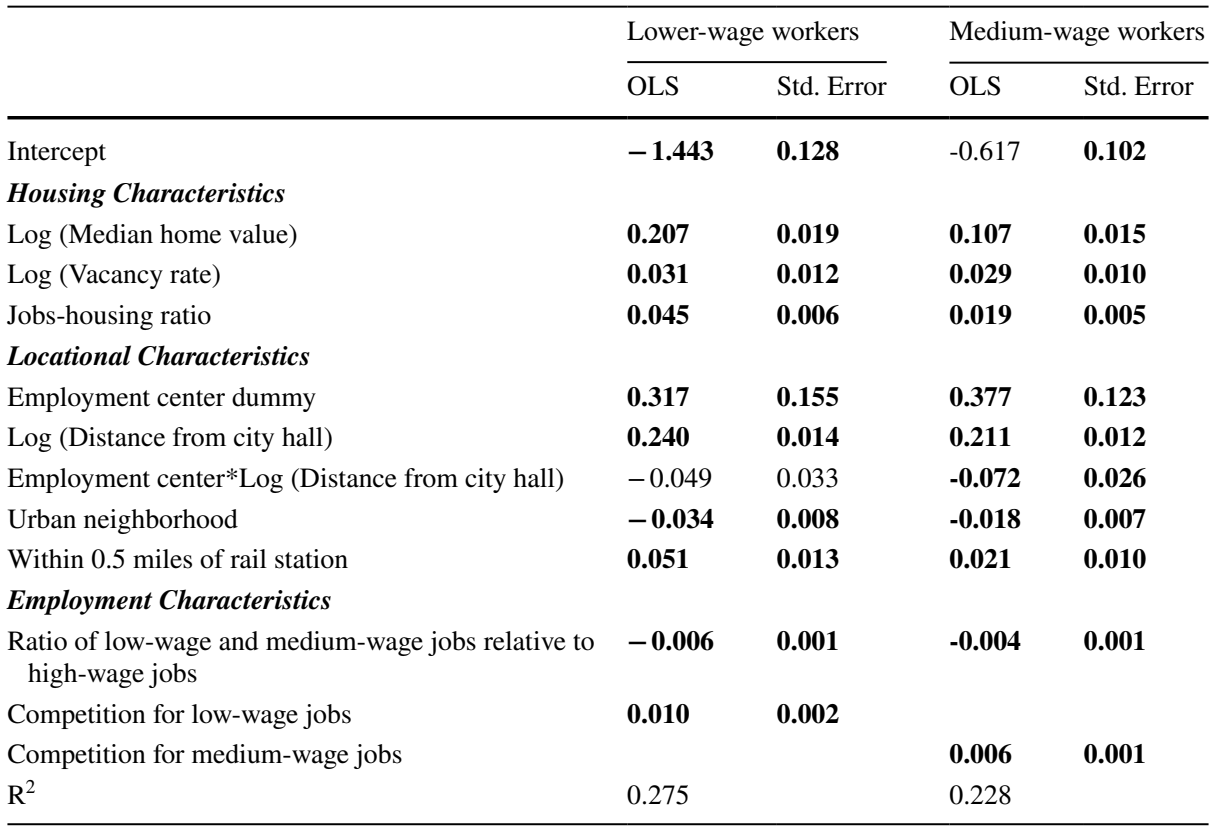

Values shown in bold are significant at $p<0.05$

Acknowledgements This study was made possible through California Statewide Transportation Research Program funding received by the University of California Institute of Transportation Studies from the State of California through the Public Transportation Account and the Road Repair and Accountability Act of 2017 (Senate Bill 1).

Authors' contributions EB developed the funding proposal including the research question and analytical approach, supervised all research, wrote and edited the manuscript. FS helped guide the research, analyzed the data, wrote and edited the manuscript.

\section{Declarations}

Conflict of interest On behalf of all authors, the corresponding author states that there is no conflict of interest.

Open Access This article is licensed under a Creative Commons Attribution 4.0 International License, which permits use, sharing, adaptation, distribution and reproduction in any medium or format, as long as you give appropriate credit to the original author(s) and the source, provide a link to the Creative Commons licence, and indicate if changes were made. The images or other third party material in this article are included in the article's Creative Commons licence, unless indicated otherwise in a credit line to the material. If material is not included in the article's Creative Commons licence and your intended use is not permitted by statutory regulation or exceeds the permitted use, you will need to obtain permission directly from the copyright holder. To view a copy of this licence, visit http://creativecommons.org/licenses/by/4.0/. 


\section{References}

Acolin, A., Wachter, S.: Opportunity and housing access. Cityscape 19, 135-150 (2017)

Alonso, W.: Location and land use. Harvard University Press, Cambridge, MA (1964)

Angel, S., Blei, A.M.: The spatial structure of American cities: the great majority of workplaces are no longer in CBDs, employment sub-centers, or live-work communities. Cities 51, 21-35 (2016). https:// doi.org/10.1016/j.cities.2015.11.031

Anselin, L.: Under the hood Issues in the specification and interpretation of spatial regression models. Agric. Econ. 27, 247-267 (2002). https://doi.org/10.1111/j.1574-0862.2002.tb00120.x

Antipova, A.: Analysis of commuting distances of low-income workers in memphis metropolitan area. TN. Sustainability. 12, 1209 (2020). https://doi.org/10.3390/su12031209

Bailey, K.A., Spletzer, J.R.: A New way to measure how many Americans work more than one job, https:// www.census.gov/library/stories/2021/02/new-way-to-measure-how-many-americans-work-more-thanone-job.html

Baker, D.M., Lee, B.: How does light rail transit (LRT) impact gentrification? evidence from fourteen US urbanized areas. J. Plan. Educ. Res. 39, 35-49 (2019). https://doi.org/10.1177/0739456X17713619

Benner, C., Karner, A.: Low-wage jobs-housing fit: identifying locations of affordable housing shortages. Urban Geogr. 37, 883-903 (2016). https://doi.org/10.1080/02723638.2015.1112565

Blumenberg, E., King, H.: Low-income workers, residential location, and the changing commute in the United States. Built Environ. 45, 563-581 (2019). https://doi.org/10.2148/benv.45.4.563

Blumenberg, E., Ong, P.: Job accessibility and welfare usage: evidence from Los Angeles. J. Policy Anal. Manage. 17, 639-657 (1998). https://doi.org/10.1002/(SICI)1520-6688(199823)17:4\% 3c639::AID-PAM3\%3e3.0.CO;2-R

Boarnet, M.G., Bostic, R.W., Burinskiy, E.: Gentrification near rail transit areas: a micro-data analysis of moves into los angeles metro rail station areas. UC Davis National Center for Sustainable Transportation, Davis, CA (2018)

Bunel, M., Tovar, E.: Key issues in local job accessibility measurement: different models mean different results. Urban Stud. 51, 1322-1338 (2014). https://doi.org/10.1177/0042098013495573

U.S. Census Bureau, Current Population Survey: 1960 to 2020 Annual Social and Economic Supplements (CPS ASEC). author, Washington, D.C. (2019)

Cervero, R.: Jobs-housing balancing and regional mobility. J. Am. Plann. Assoc. 55, 136-150 (1989). https://doi.org/10.1080/01944368908976014

Cervero, R.: Jobs-housing balance revisited: Trends and impacts in the San Francisco Bay Area. J. Am. Plann. Assoc. 62, 492-511 (1996). https://doi.org/10.1080/01944369608975714

Cervero, R., Wu, K.-L.: Sub-centring and commuting: evidence from the San Francisco Bay Area, 1980-90. Urban Stud. 35, 1059-1076 (1998). https://doi.org/10.1080/0042098984484

Chacon-Hurtado, D., Gkritza, K., Fricker, J.D., Yu, D.J.: Exploring the role of worker income and workplace characteristics on the journey to work. Int. J. Sustain. Transp. 13, 553-566 (2019). https://doi. org/10.1080/15568318.2018.1490466

Cheshire, P., Hilber, C.A.L., Koster, H.R.A.: Empty homes, longer commutes: the unintended consequences of more restrictive local planning. J. Public Econ. 158, 126-151 (2018). https://doi.org/10. 1016/j.jpubeco.2017.12.006

Cooke, T.J., Denton, C.: The suburbanization of poverty? an alternative perspective. Urban Geogr. 36, 300-313 (2015). https://doi.org/10.1080/02723638.2014.973224

Crane, R.: The Influence of uncertain job location on urban form and the journey to work. J. Urban Econ. 39, 342-356 (1996)

Crane, R.: Is there a quiet revolution in women's travel? Revisiting the gender gap in commuting. J. Am. Plann. Assoc. 73, 298-316 (2007). https://doi.org/10.1080/01944360708977979

Davidson, J.H., Ryerson, M.S.: Building reverse commute typologies through urban and suburban socioeconomic characteristics. Cities 81, 180-189 (2018). https://doi.org/10.1016/j.cities.2018.04.007

Dey, M., Frazis, H., Loewenstein, M., Sun, H.: Ability to work from home: evidence from two surveys and implications for the labor market in the COVID-19 pandemic. Mon. Labor Rev. (2020). https:// doi.org/10.21916/mlr.2020.14

Dominie, W.: Is just growth smarter growth?: the effects of gentrification on transit ridership and driving in los angeles' transit station area neighborhoods. University of California, Los Angeles, Los Angeles, CA (2012)

Dougherty, C., Burton, A.: A 2:15 alarm, 2 trains and a but get her to work by 7 A.M., (2017)

Douglas, M.J., Watkins, S.J., Gorman, D.R., Higgins, M.: Are cars the new tobacco? J. Public Health. 33, 160-169 (2011). https://doi.org/10.1093/pubmed/fdr032 
Fischel, W.A.: An economic history of zoning and a cure for its exclusionary effects. Urban Stud. 41, 317-340 (2004)

Frey, W.H.: US population disperses to suburbs, exurbs, rural areas, and "middle of the country" metros., Washington D.C. (2018)

Gao, Q.-L., Li, Q.-Q., Zhuang, Y., Yue, Y., Liu, Z.-Z., Li, S.-Q., Sui, D.: Urban commuting dynamics in response to public transit upgrades: a big data approach. PLOS ONE 14(10), e0223650 (2019). https://doi.org/10.1371/journal.pone.0223650

Giuliano, G.: Is jobs-housing balance a transportation issue? Transp. Res. Rec. 1305, 305-312 (1991)

Giuliano, G., Small, K.A.: Subcenters in the Los Angeles region. Reg. Sci. Urban Econ. 21, 163-182 (1991). https://doi.org/10.1016/0166-0462(91)90032-I

Giuliano, G., Redfearn, C., Agarwal, A., Li, C., Zhuang, D.: Employment concentrations in Los Angeles, 1980-2000. Environ. Plan. Econ. Space. 39, 2935-2957 (2007). https://doi.org/10.1068/a393

Glaeser, E.: Reforming land use regulations. Brookings Institution, Washington, D.C. (2017)

Glaeser, E.L., Kahn, M.E., Rappaport, J.: Why do the poor live in cities? the role of public transportation. J. Urban Econ. 63, 1-24 (2008)

Glaeser, E.L., Kahn, M.E., Arnott, R., Mayer, C.: Decentralized Employment and the Transformation of the American City [with Comments]. Brook.-Whart. Pap. Urban Aff. 1-63 (2001)

Golgher, A.B., Voss, P.R.: How to interpret the coefficients of spatial models: spillovers direct and indirect effects. Spat. Demogr. 4, 175-205 (2016). https://doi.org/10.1007/s40980-015-0016-y

Gordon, P., Richardson, H.W., Wong, H.L.: The distribution of population and employment in a Polycentric City: the case of Los Angeles. Environ. Plan. Econ. Space. 18, 161-173 (1986). https://doi.org/10. 1068/a180161

Gottlieb, P.D., Lentnek, B.: Spatial mismatch is not always a central-city problem: an analysis of commuting behaviour in Cleveland, Ohio, and its suburbs. Urban Stud. 38, 1161-1186 (2001). https://doi.org/10. 1080/00420980120051701

Graham, M.R., Kutzbach, M.J., McKenzie, B.: Design Comparison of LODES and ACS Commuting Data Products. U.S. Census Bureau, Center for Economic Studies, Washington, D.C. (2014)

Hamilton, B.W.: Wasteful commuting. J. Polit. Econ. 90, 1035-1053 (1982)

Hamilton, B.W., Röell, A.: Wasteful commuting. J. Polit. Econ. 90, 1035-1053 (1982). https://doi.org/10. $1086 / 261107$

Hanson, S.: Gender and mobility: new approaches for informing sustainability. Gend. Place Cult. 17, 5-23 (2010). https://doi.org/10.1080/09663690903498225

Holder, S.: Where commuting is out of control, (2018)

Horner, M.W.: Extensions to the concept of excess commuting. Environ. Plan. Econ. Space. 34, 543-566 (2002). https://doi.org/10.1068/a34126

Horner, M.W., Schleith, D.: Analyzing temporal changes in land-use-transportation relationships: A LEHDbased approach. Appl. Geogr. 35, 491-498 (2012). https://doi.org/10.1016/j.apgeog.2012.09.006

Howell, A.J., Timberlake, J.M.: Racial and ethnic trends in the suburbanization of poverty in U.S. metropolitan areas, 1980-2010. J. Urban Aff. 36, 79-98 (2014). https://doi.org/10.1111/juaf.12030

Hu, L.: Job accessibility of the poor in Los Angeles. J. Am. Plann. Assoc. 81, 30-45 (2015). https://doi.org/ 10.1080/01944363.2015.1042014

Hu, L., Schneider, R.J.: Different ways to get to the same workplace: How does workplace location relate to commuting by different income groups? Transp. Policy. 59, 106-115 (2017). https://doi.org/10.1016/j. tranpol.2017.07.009

Joint Center for Housing Studies: America's Rental Housing 2020. Harvard University, Cambridge, MA (2020b)

Joint Center for Housing Studies: The State of the Nation's Housing 2020. Harvard University, Cambridge, MA (2020a)

Kahn, M.E.: Gentrification trends in new transit-oriented communities: evidence from 14 Cities that expanded and built rail transit systems. Real Estate Econ. 35, 155-182 (2007). https://doi.org/10. 1111/j.1540-6229.2007.00186.x

Kain, J.F.: Housing segregation, Negro employment, and metropolitan decentralization. Q. J. Econ. 82, 175-197 (1968)

Kawabata, M., Shen, Q.: Commuting inequality between cars and public transit: the case of the San Francisco Bay Area, 1990-2000. Urban Stud. 44, 1759-1780 (2007). https://doi.org/10.1080/0042098070 1426616

Kneebone, E.: Job sprawl stalls: the great recession and metropolitan employment location. Brookings Institution, Washington, D.C. (2013)

Kneebone, E., Garr, E.: The suburbanization of poverty: trends in metropolitan America, 2000 to 2008. The Brookings Institution, Washington, D.C. (2010) 
Kneebone, E., Holmes, N.: The growing distance between people and jobs in metropolitan America. Metropolitan Policy Program, Brookings Institution, Washington, D.C. (2016)

Lane, J.: The role of job turnover in the low-wage labor market. In: Kaye, K. and Nightingale, D.S. (eds.) The Low-Wage Labor Market. Challenges and Opportunities for Economic Self-Sufficiency. pp. 185198. Urban Institute, Washington, D.C. (2000)

Levine, J.: rethinking accessibility and jobs-housing balance. J. Am. Plann. Assoc. 64, 133-149 (1998). https://doi.org/10.1080/01944369808975972

Lopez, S.: Her six-hour commute each day seems crazy, but her affordable rent is not, (2017)

Manville, M., Lens, M., Monkkonen, P.: Zoning and affordability: a reply to Rodríguez-Pose and Storper. Urban Stud. (2020). https://doi.org/10.1177/0042098020910330

Martin, R.W.: The adjustment of black residents to metropolitan employment shifts: how persistent is spatial mismatch? J. Urban Econ. 50, 52-76 (2001). https://doi.org/10.1006/juec.2000.2211

McGuckin, N., Fucci, A.: Summary of Travel Trends: 2017 National Household Travel Survey. Federal Highway Administration, US Department of Transportation. Washington, DC (2018)

Mills, E.S.: An Aggregative Model of Resource Allocation in a Metropolitan Area. Am. Econ. Rev. 57, 197-210 (1967)

Morris, E.A., Ettema, D., Zhou, Y.: Which activities do those with long commutes forego, and should we care? Transp. Res. Interdiscip. Perspect. 5, 100119 (2020). https://doi.org/10.1016/j.trip.2020.100119

Murray, C., Schuetz, J.: Housing in the US is too expensive, too cheap, and just right. It depends on where you live. Brookings Institution, Washington, D.C. (2018)

Muth, R.F.: Cities and housing. The University of Chicago Press, Chicago (1969)

Nightingale, D.S., Wandner, S.A.: Informal and nonstandard employment in the United States. Implications for Low-Income Working Families. The Urban Institute, Washington, D.C. (2011)

Pathak, R., Wyczalkowski, C.K., Huang, X.: Public transit access and the changing spatial distribution of poverty. Reg. Sci. Urban Econ. 66, 198-212 (2017). https://doi.org/10.1016/j.regsciurbeco.2017. 07.002

Peng, Z.-R.: The Jobs-Housing Balance and Urban Commuting. Urban Stud. 34, 1215-1235 (1997). https://doi.org/10.1080/0042098975600

Plaut, P.O.: The intra-household choices regarding commuting and housing. Transp. Res. Part Policy Pract. 40, 561-571 (2006). https://doi.org/10.1016/j.tra.2005.10.001

Raphael, S., Stoll, M.A.: Job Sprawl and the Suburbanization of Poverty. Metropolitan Policy Program, Brookings Institution, Washington D.C. (2010)

Renne, J.L., Tolford, T., Hamidi, S., Ewing, R.: The cost and affordability paradox of transit-oriented development: a comparison of housing and transportation costs across transit-oriented development, hybrid and transit-adjacent development station typologies. Hous. Policy Debate. 26, 819834 (2016). https://doi.org/10.1080/10511482.2016.1193038

Rodríguez-Pose, A., Storper, M.: Housing, urban growth and inequalities: The limits to deregulation and upzoning in reducing economic and spatial inequality. Urban Stud. 57, 223-248 (2020). https://doi. org/10.1177/0042098019859458

Ruggles, S., Flood, S., Foster, S., Goeken, R., Pacas, J., Schouweiler, M., Sobek, M.: IPUMS USA: Version 11.0. University of Minnesota, Minneapolis, MN (2021)

Schleith, D., Widener, M., Kim, C.: An examination of the jobs-housing balance of different categories of workers across 26 metropolitan regions. J. Transp. Geogr. 57, 145-160 (2016). https://doi.org/ 10.1016/j.jtrangeo.2016.10.008

Schleith, D., Widener, M.J., Kim, C., Horner, M.W.: Categorizing urban form for the largest metro regions in the U.S. Using the excessive commuting framework. Built Environ. 45, 450-461 (2019). https://doi.org/10.2148/benv.45.4.450

Schuetz, J.: Cost, crowding, or commuting? Housing stress on the middle class, https://www.brookings. edu/research/cost-crowding-or-commuting-housing-stress-on-the-middle-class/, (2019)

Schwanen, T., Dieleman, F.M., Dijst, M.: The impact of metropolitan structure on commute behavior in the netherlands: a multilevel approach. Growth Change. 35, 304-333 (2004). https://doi.org/10. 1111/j.1468-2257.2004.00251.x

Shen, Q.: A spatial analysis of job openings and access in a U.S. metropolitan area. J. Am. Plann. Assoc. 67, 53-68 (2001). https://doi.org/10.1080/01944360108976355

Sisson, P.: Supercommuters, skyrocketing commutes, and America's affordable housing crisis, https:// archive.curbed.com/2017/6/20/15834514/rent-transportation-commute-affordable-housing, (2017)

Somerville, T., Mayer, C.: Government regulation and changes in the affordable housing stock. Federal Reserve Bank of New York, New York (2003)

State of California. Employment Development Department: Exempt Employment. author, Sacramento, CA (nd) 
Stoll, M.: Job sprawl and the spatial mismatch between blacks and jobs. The Brookings Institution, Washington, D.C. (2005)

Stoll, M.A., Holzer, H.J., Ihlanfeldt, K.R.: Within cities and suburbs: Racial residential concentration and the spatial distribution of employment opportunities across sub-metropolitan areas. J. Policy Anal. Manage. 19, 207-231 (2000)

Sultana, S.: Job/housing imbalance and commuting time in the Atlanta metropolitan area: exploration of causes of longer commuting time. Urban Geogr. 23, 728-749 (2002)

Taylor, M.: California's High Housing Costs. Causes and Consequences. Legislative Analyst's Office, State of California, Sacramento, CA (2015)

Tu, J.: Low pay and long, pricey commute often go hand in hand, (2015)

U.S. Census Bureau: Longitudinal Employer-Household Dynamics Origin-Destination Employment Statistics (LODES) [data]. author, Washington, D.C. (2015)

United States Government Accountability Office: Rental Housing. As More Households Rent, the Poorest Face Affordability and Housing Quality Challenges. Author, Washington, D.C. (2020)

Voulgaris, C.T., Taylor, B.D., Blumenberg, E., Brown, A., Ralph, K.: Synergistic neighborhood relationships with travel behavior: An analysis of travel in 30,000 US neighborhoods. J. Transp. Land Use. 10, 437-461 (2017)

Weber, J., Sultana, S.: Employment Sprawl, Race and the Journey to Work in Birmingham. Alabama. Southeast. Geogr. 48, 53-74 (2008)

White, M.J.: Commuting and congestion: a simulation model of a decentralized metropolitan area. Real Estate Econ. 18, 335-368 (1990). https://doi.org/10.1111/1540-6229.00527

Whittemore, A.H.: Exclusionary zoning. J. Am. Plann. Assoc. (2020). https://doi.org/10.1080/01944363. 2020.1828146

Zonta, M.: Expanding the Supply of Affordable Housing for Low-Wage Workers. Center for American Progress (2020)

Publisher's Note Springer Nature remains neutral with regard to jurisdictional claims in published maps and institutional affiliations.

Evelyn Blumenberg is a Professor of Urban Planning at the UCLA Luskin School of Public Affairs. Her research examines transportation equity, travel behavior, and low-wage labor markets.

Fariba Siddiq is an urban planning doctoral student and a researcher in the Institute of Transportation Studies at UCLA. 